\title{
Less is More in Hong Kong: Investigation of Biscriptal and Trilingual Development Among Chinese Twins in a (Relatively) Small City
}

\author{
Simpson W. L. Wong, ${ }^{1}$ Connie Suk-Han Ho, ${ }^{2}$ Catherine McBride, ${ }^{3}$ Bonnie Wing-Yin Chow, ${ }^{4}$ \\ and Mary Miu Yee Waye ${ }^{5}$ \\ ${ }^{1}$ Department of Psychology, The Education University of Hong Kong, Taipo, Hong Kong \\ ${ }^{2}$ Department of Psychology, The University of Hong Kong, Pokfulam, Hong Kong \\ ${ }^{3}$ Department of Psychology, The Chinese University of Hong Kong, Shatin, Hong Kong \\ ${ }^{4}$ Department of Applied Social Sciences, City University of Hong Kong, Kowloon Tong, Hong Kong \\ ${ }^{5}$ The Nethersole School of Nursing and School of Biomedical Sciences, The Chinese University of Hong Kong, Shatin, \\ Hong Kong
}

\begin{abstract}
One salient characteristic of twin studies and the related behavioral genetics paradigm is the requirement of a large sample size. Countries or regions that are large in size and highly populated are at an advantage when implementing twin studies. However, given the fascinating and promising results obtained from twin studies, many researchers based in smaller countries or regions may still want to conduct twin studies in order to address local and theoretical issues. In this article, we have outlined the development of twin studies in Hong Kong, one of the Special Administrative Regions of China. The historical development and design of the two major twin studies of language and reading development implemented within Hong Kong are discussed, providing insights to researchers who also aspire to conduct twin studies in small regions.
\end{abstract}

Keywords: Hong Kong, twin studies, language and reading development

\section{The Unique Linguistic Background in Hong Kong}

Hong Kong is a small Special Administrative Region of China with a population size of over 7 million. Among the population, over $90 \%$ are Han Chinese who speak Cantonese as their mother tongue. Due to the history of British colonization, English is a compulsory language in the Hong Kong education system and one of the two official languages besides Chinese. Even though Cantonese is the dialect spoken by the majority of Hong Kong people, $\mathrm{Pu}$ tonghua (also known as Mandarin) has gained increasing importance as it is the official spoken language of mainland China. Since 1998, Putonghua has been a compulsory subject in primary and secondary schools in Hong Kong, with some schools using Putonghua as a medium of instruction. According to a large-scale survey conducted on $32.7 \%$ of all primary schools in Hong Kong, $90 \%$ of the school principals claimed that their graduates achieved at least average proficiency in Putonghua in the language benchmark test taken prior to graduation (Wang \& Kirkpatrick, 2015). As an international city, many Hong Kong Chinese residents learn English, and the role of English has remained important even after the handover of sovereignty to the Central Chi- nese government in 1997. Hong Kong students start learning English as a compulsory subject at the age of 3 years, when they enter kindergarten level one, and generally obtain intermediate to high English proficiency levels as indicated by a mean band score of 6.3 in IELTS (IELTS Partners, 2012) achieved by academic candidates. Thus, children's language and reading skills can be assessed from as young as 3 years old. Given the implementation of mandatory English and Putonghua education in Hong Kong, a homogeneous twin sample that shares a similar language education background can be obtained for addressing a series of critical issues related to bilingualism and trilingualism (Cantonese, Mandarin, English). Despite being a small city, there are eight government-funded universities and one private university, as well as many active researchers in Hong Kong. As such, there are a large variety of research

RECEIVED 22 August 2016; ACCEPTED 11 October 2016. First published online 5 December 2016.

ADDRESS FOR CORRESPONDENCE: Dr Simpson Wong, Department of Psychology, The Education University of Hong Kong, Taipo, Hong Kong. E-mail: swlwong@eduhk.hk 
TABLE 1

\begin{tabular}{|c|c|c|c|c|c|c|c|}
\hline Type of birth & 2009 & 2010 & 2011 & 2012 & 2013 & 2014 & 2015 \\
\hline 1. Singletons & 79,749 & 86,059 & 92,545 & 89,169 & 55,215 & 60,354 & 58,071 \\
\hline 2. Twins & 2,304 & 2,474 & 2,858 & 2,344 & 1,830 & 1,930 & 1,798 \\
\hline 3. Triplets and other higher order multiple births & 42 & 51 & 48 & 45 & 39 & 21 & 9 \\
\hline Total & 82,095 & 88,584 & 95,451 & 91,558 & 57,084 & 62,305 & 59,878 \\
\hline
\end{tabular}

Note: Data sourced from Census and Statistics Department, Hong Kong SAR, 2015.

topics studied by many scholars in Hong Kong. Moreover, the necessary technical support for conducting a twin study is available. Given the unique language background of the city, the study of learning English as a second language, bilingualism, and multilingualism are all popular research topics in Hong Kong. In this article, we will review the recent twin studies conducted in Hong Kong and propose new research ideas both for Hong Kong and for other cities with similar multilingual backgrounds.

\section{The Pioneering Systematic Territory-Wide Twin Study in Hong Kong}

Both the sabbatical leave of Professor Connie Ho from the University of Hong Kong and her participation in the annual International Twin Workshop, hosted by the Institute for Behavioral Genetics at Colorado, contributed to the initiation of a pioneering twin study conducted in Hong Kong. Although no twin study of child development had been carried out before 2007, the Research Grants Council of Hong Kong generously sponsored the first systematic twin study of language and reading development in Chinese children (e.g., Chow et al., 2011, 2013; Ho et al., 2012; Wong, 2013). This study, which is known as the Chinese Twin Study (CTS) of reading development, also gained support from the Wellcome Trust Programme grant 082498/Z/07/Z awarded to Professor D. V. M. Bishop. In this pioneering twin study, Professor Mary Waye, from The Chinese University of Hong Kong, provided support for zygosity testing. The composition of this research team highlights the interdisciplinary nature of behavioral genetic studies.

As no previous studies had been carried out for reference, the team had to devise multiple participant recruitment strategies to ensure that enough twin participants were obtained. According to the Census and Statistics Department in Hong Kong, around 1,000 pairs of twins are born each year in Hong Kong (see Table 1 for details).

The team was therefore confident that they could recruit enough twins within the 3-year project period. Without any help from a territory-wide governmental network, twin participants of this study were mainly recruited through the help offered by the personnel of kindergartens and primary schools. School personnel were approached through written and telephone communication. Schools that had twin students then provided the team with contact details of the twins' families for follow-up. Next, the research assistants arranged testing sessions to take place either at the participants' schools or homes. The participating schools included 135 kindergartens and 96 primary schools of Hong Kong, which comprised $15 \%$ and $17 \%$ of all the kindergartens and primary schools in Hong Kong for 2008, respectively (see Table 2 for details).

It is possible that the research team had failed to reach and contact many of the twins. Apart from through schools, some participants were obtained through referrals by non-governmental organizations, churches, parental newsgroups, and the project's website (http://hkoxtwin. googlepages.com), as well as through posters advertising the twin study. There were also a few participants who contacted the research team upon reading a newspaper article that reported the project. As this twin study was a pioneering one in Hong Kong, the parents of twins were enthusiastic and supportive of the project. In the year 2008-2009, two full-time research assistants recruited a total of 400 pairs of twins aged between 3 and 11 years.

\section{The Advantages of Conducting a Twin Study in a (Relatively) Small City}

Despite the limited number of twins available in a relatively small city, one prominent advantage of conducting a twin study in Hong Kong is the efficiency of data collection. Given the established research participation culture among local schools in Hong Kong, the scheduling and administration of testing is normally achieved within one to two weeks after parental consent is obtained. The relatively short travel distance and convenient transportation system within Hong Kong also allows testing to be completed within a short period of time. Furthermore, when testing cannot be completed for some reason (e.g., children are unwell or unavailable), the makeup testing can be done shortly after the absence.

Another advantage of running the project in a small city is that twins in Hong Kong experience a relatively homogeneous culture and education system. Therefore, the common environment factor may be relatively stable for all twins. Another factor, unique to Hong Kong, is the fact that it has the highest proportion of domestic workers in total employment of all the industrialized, high-income economies (International Labour Office, 2010). Based on samples taken from the Hong Kong 2006 Population Bi-Census, there were 62,218 Filipino foreign domestic helpers (FDH) who worked in households where there was at least one child 


\begin{tabular}{lll}
\hline TABLE 2 & & \\
Number of Twins Recruited from Kindergartens and Primary Schools in Hong Kong in the CTS Study \\
\hline $\begin{array}{l}\text { The number of sets of twins per } \\
\text { kindergarten or school }\end{array}$ & Kindergartens & Primary schools \\
\hline One & 96 & 60 \\
Two & 27 & 14 \\
Three & 8 & 9 \\
Four & 1 & 8 \\
Five & 2 & 3 \\
Six & 0 & 1 \\
Seven & 1 & 0 \\
Eight & 0 & 1 \\
Total & $135 / 889$ kindergartens in Hong Kong in the & $96 / 557$ schools in Hong Kong in the year \\
& year 2008 & 2008 \\
& (Hong Kong Education Bureau, 2012) & (Hong Kong Education Bureau, 2012) \\
\hline
\end{tabular}

aged 12 years or below. Past research has shown that young children (kindergarten age), whose home has a Filipino domestic helper, tend to demonstrate better vocabulary knowledge in English but poorer vocabulary knowledge in Cantonese (Chan \& McBride-Chang, 2005). As shown in a recent study, Hong Kong primary school children who live with a Filipino domestic helper often obtain a significantly higher score for English (Tang \& Yung, 2016). While Hong Kong domestic workers made up $7 \%$ of total employment in 2009, other countries that have a similar situation such as Singapore (6\%), Cyprus (4.4\%), Spain (4\%), Portugal $(3.4 \%)$, France $(2.3 \%)$, and Greece $(2 \%)$, could contribute data on the effect of live-in FDHs on language acquisition in the future.

\section{The Major Findings of the Chinese Twin Study (CTS) of Reading Development}

The first systematic twin study was conceptualized within the framework of contemporary behavioral genetics. Based on the idea of 'bootstrapping' (Werker \& Yeung, 2005), we included language and reading variables that are linked developmentally. Speech perception and production serve as the foundation for later phonological development. Such development, in turn, fosters written and spoken vocabulary learning as well as subsequent discourse skills. This link was evidenced in our pioneering twin studies (Wong, Bishop et al., 2009; Wong, Chow et al., 2013; Wong, Ho et al., 2010). In addition, we were also the first to provide univariate estimates of genetic and environmental effects on Chinese and English language (speech perception and vocabulary knowledge; Wong et al., 2014) and reading (word, sentence, and passage reading; Ho et al., 2012) abilities, as well as related metalinguistic skills (tone awareness, morphological awareness, orthographic skills, and rapid naming skills; Chow et al., 2011, 2013). Apart from univariate twin analysis, we conducted multivariate twin analyses to test both intra- and inter-language development. The Chinese version of the Simple View of Reading Model (Ho et al., 2012) and the Generalist Genes Hypothesis (Chow et al., 2013) were tested using a twin study approach. Additionally, the genetic and environmental overlap between Chinese and English language and reading skills were explored (Wong et al., 2014). Additionally, a genetics method for identifying the zygosity of Chinese twins was also developed and reported (Lim et al., 2011). Findings from this study by Lim et al. (2011) suggested that using naked-eye observation to differentiate between monozygotic (MZ) and dizygotic (DZ) twins was unreliable, as eye and hair color are more or less the same across the Han Chinese population.

\section{An Ongoing Twin Study as an Extension of the Chinese Twin Study (CTS) of Reading Development}

Further to the aforementioned twin study, the Research Grants Council Hong Kong continued to provide funding support for twin research. Another territory-wide twin study was funded in 2014 to investigate reading development in both Chinese and English among Chinese children. The extended project was co-supervised by Professor Catherine McBride from The Chinese University of Hong Kong and Professor Connie Ho from the University of Hong Kong. This project proposed to examine not only behavioral and cognitive-linguistics skills in Chinese reading development, but also both Chinese and English reading skills development and the affective factors that may have an impact on language and reading development. In addition, language and reading performances manifested at the neurological and molecular genetic levels were investigated. Another aim of this extended project was to examine the developmental trend in word reading using a longitudinal twin design. Within this ongoing study, the sample size was improved, being larger yet also targeted to a narrower age range. Another improvement is the additional use of the genome wide association studies (GWAS) approach to studying more genes that might be important in language development. This is taking place with the help of Professors Simon Fisher, Silvia Paracchini, and Mary Waye. All of these improvements were made possible with greater research support from local and overseas researchers. In this extended twin study, the size of the research team was 
also expanded, and the team members included researchers with more diverse backgrounds.

Similar to the previous twin study, participant recruitment in the ongoing study mainly relies on the assistance of local schools. The research team has also taken advantage of more widespread use of social media such as Facebook (HK Bilingual Twin Study), Whatsapp, and the ebanners of websites, and has been able to recruit participants through these forms of social media. The Facebook page of the project also serves as a platform for the dissemination of project updates and useful information for twins and their parents. Additionally, the Facebook page is a registry platform for the research team to maintain the participants' records and engagement, which is important for conducting a longitudinal twin study. In addition, booklets and posters were created and distributed to NGOs, schools, and related governmental departments. Given the exciting findings obtained from the previous twin study and other research on literacy development in Hong Kong available, the research team organized public seminars to attract more twin participants and enhance the publicity of the project. With heightened public awareness of the twin study, it is expected that participant recruitment will be made easier.

There are also a number of web-based tools facilitating the twin recruitment. For example, an e-form created with Google Page hosted at the project website (http://www. psychology.hku.hk/hktwin/main.html) allows participants to sign up for the experiment via the internet. This practice has streamlined the administration procedure and reduced the cost of printing application forms. Additionally, lucky draws are held on a regular basis to award those who have referred twin participants to the research team.

In this new project, more data is requested from each participant, and therefore the testing administration time has increased. Rather than a single session, multiple sessions are planned, of which two to three are designated for behavioral-cognitive testing and one for a subset of children for electrophysiological testing. As this extended twin project involves researchers from four local universities, more laboratories are available for testing. In other words, parents have greater choice when selecting a testing venue.

Another new investigative focus in this new twin study is the inclusion of a comparable sample of singletons. By comparing twins and non-twins, the study considers children's learning progress and whether the two groups have comparable educational achievements. This study, sponsored by The Chinese University of Hong Kong, will add new findings regarding the extent to which 'twins are lagging behind' (e.g., Rutter et al., 2003; Webbink et al., 2008).

\section{The MZ/DZ Ratios and Gender of the Twins}

Aside from the sample size, the monozygotic:dizygotic (MZ:DZ) twinning ratio leads to some concerns. As shown in several studies conducted on Asian populations, the MZ:DZ twinning ratio is expected to be lower than that exhibited in non-Asian countries (Chen et al., 2010; Gan et al., 2007; Imaizumi, 2003). Similarly, a same-sex DZ to MZ twin ratio of 0.35 was observed in the aforementioned CTS of reading development (e.g., Chow et al., 2011, 2013; Ho et al., 2012). Unlike within the previous study, oppositesex DZ twins are included, enabling a larger sample size and thus increasing the statistical power of the study. The effect of gender will be corrected by statistical methods.

\section{Future Research Directions and Sustainability of Twin Study in Hong Kong Locally and Globally}

Despite the short history of twin research in Hong Kong, the provision of a unique language-learning environment makes it an important research topic. Given that it has been less than 10 years since the first territory-wide twin study commenced in Hong Kong, a larger sample size may be obtained in the foreseeable future in a cumulative manner, similar to other large-scale twin projects around the world. At the time when we prepared this article, Dr Timothea Toulopoulou from The University of Hong Kong had just completed a twin study of schizophrenia endophenotypes on a pan-European twin sample. She is also conducting another twin study on affective development in adolescents. We expect that more new topics related to twin study will emerge in the near future. Continual and increasing financial support from the local grants council, technical support from researchers, and support from schools and parents are all key to success. For more efficient twin recruitment in the long run, the support of local governmental units is needed, such as the Department of Health or Hospital Authority. The establishment of a territory-wide twin registry is definitely of prime importance. All the above improvements will also speed up the recruitment of twins who have specific learning difficulties and allow researchers in Hong Kong to examine the genetic and environmental influences and risks on a range of learning difficulties. With the implementation of the 'biliteracy and trilingualism' education policy in Hong Kong, research on the interplay of genes and environment on Cantonese, English, and Putonghua learning is necessary for understanding education and child development in the local context. Extending from previous findings of partial genetic and environmental overlap between spoken and written language performances in a group of Australian twins learning a mix of second languages (Coventry et al., 2012), bilingual twin studies conducted in Hong Kong will further reveal the genetic and environmental overlap (and independence) among the three spoken and two written languages. To date, medical-related twin studies are under-represented in Hong Kong. It is necessary to research more medical and physical traits that will carry more culture- and ethnic-specific implications. 
As an international city, international collaborations are welcomed in Hong Kong. For instance, Professor McBride from The Chinese University of Hong Kong and Dr Silvia Paracchini from the University of St. Andrews (Scotland) have recently collaborated on a study on handedness in the twin sample.

With twin studies blossoming in Hong Kong, talented researchers will be more likely to require additional skills for conducting twin studies, such as advanced modeling statistics. This twin research culture will also promote education on behavioral genetics, and more locally trained behavioral geneticists are expected in the future.

With the close proximity to other cities in Southern China, in which spoken languages (Cantonese, Putonghua, and English as a second language) are shared, there is a possibility to combine the twin data across these cities. This may include those who have already established a twin registry and are experienced in conducting twin research (e.g., Guangzhou; Zheng et al., 2012). It may also be possible to initiate pioneering twin studies in a nearby city, such as Macau, since the demographic features of children speaking languages are similar to those of Hong Kong children. Given the similar language background but different education systems of Hong Kong and these proximal cities, the aggregated dataset may prove to be invaluable in informing the role of environmental influences on heritability.

\section{Acknowledgments}

We would like to thank Professor Dorothy Bishop for her comments and Ms Cheuk Wa Wong and Ms Jessica Dealey for their technical assistance. This work was supported by the Collaborative Research Fund of the Research Grants Council (RGC) of Hong Kong (grant number CUHK8/CRF/13G).

\section{Conflict of Interest}

None.

\section{References}

Census and Statistics Department, Hong Kong SAR. (2015). Statistics of known live births. Hong Kong SAR: Demographic Statistics Section.

Chan, T. Y., \& McBride-Chang, C. (2005). Environment and bilingualism in Hong Kong kindergartners: The impact of foreign domestic helpers on early language-learning. Journal of Psychology in Chinese Societies, 6, 179-193.

Chen, J., Li, X., Chen, Z., Yang, X., Zhang, J., Duan, Q., \& $\mathrm{Ge}, \mathrm{X}$. (2010). Optimization of zygosity determination by questionnaire and DNA genotyping in Chinese adolescent twins. Twin Research and Human Genetics, 13, 194-200.

Chow, B. W.-Y., Ho, C. S.-H., Wong, S. W. L., Waye, M. M. Y., \& Bishop, D. V. M. (2011). Genetic and environmental influences on Chinese language and reading abilities. PLoS ONE, 6, 1-9.
Chow, B. W.-Y., Ho, C. S.-H., Wong, S. W. L., Waye, M. M. Y., \& Bishop, D. V. M. (2013). Generalist genes and cognitive abilities in Chinese twins. Developmental Science, 16, 260268.

Coventry, W., Antón-Méndez, I., Ellis, E. M., Levisen, C., Byrne, B., van Daal, V. H., \& Ellis, N. C. (2012). The etiology of individual differences in second language acquisition in Australian school students: A behavior genetic study. Language Learning, 62, 880-901.

Gan, J. P., Wu, Z. H., Tu, Z. M., \& Zheng, J. (2007). The comparison of twinning rates between urban and rural areas in China. Twin Research and Human Genetics, 10, 633-637.

Ho, C. S.-H., Chow, B. W. Y., Wong, S. W. L., Waye, M., \& Bishop, D. V. M. (2012). The genetic and environmental foundation of the simple view of reading in Chinese. PLoS ONE, 7, e47872.

Hong Kong Education Bureau. (2012). Student enrolment statistics, 2011/12 (kindergarten, primary and secondary Levels). Hong Kong SAR: Author.

IELTS Partners. (2012). Test taker performance 2012. Retrieved from http://www.ielts.org/researchers/ analysis- of-test-data/test-taker-performance-2012.aspx.

Imaizumi, Y. (2003). A comparative study of zygotic twinning and triplet rates in eight countries, 1972-1999. Journal of Biosocial Science, 35, 287-302.

International Labour Office. (2010). Domestic workers across the world: Global and regional statistics and the extent of legal protection. Geneva: Author.

Lim, C. K. B., Yeung, V. S. Y., Yeung, T. L., Tam, A. C. Y., Ho, C. S.-H., Wong, S. W. L., ... Waye, M. M. Y. (2011). Genotype analyses using SNP (Using MALDI-TOF Mass Spectrometry) and STR (Microsatellite) Markers in the determination of zygosity status of Chinese twins, Journal of Biochemistry and Molecular Biology in the Post Genomic Era, 1, 51-64.

Rutter, M., Thorpe, K., Greenwood, R., Northstone, K., \& Golding, J. (2003). Twins as a natural experiment to study the causes of mild language delay: I: Design; twin-singleton differences in language, and obstetric risks. Journal of Child Psychology and Psychiatry, 44, 326-341.

Tang, S. H. K., \& Yung, L. C. W. (2016). Maids or mentors? the effects of live-in foreign domestic workers on children's educational achievement in Hong Kong, Education Economics, 24, 96-120.

Wang, L., \& Kirkpatrick, A. (2015). Trilingual education in Hong Kong primary schools: An overview. Multilingual Education, 5, 1-26.

Webbink, D., Posthuma, D., Boomsma, D., de Geus, J., \& Visscher, P. M. (2008). Do twins have lower cognitive ability than singletons?. Intelligence 36, 539-547.

Werker, J. F., \& Yeung, H. H. (2005). Infant speech perception bootstraps word learning. Trends in Cognitive Sciences, 9, 519-527.

Wong, S. W. L. (2013). When Lev Vygotsky meets Francis Galton: On the nature and nurture of reading development. In S. Phillipson, K. Ku \& S. N. Phillipson (Eds.), Constructing educational achievement: A sociocultural perspective (pp. 177-187). Oxford: Routledge. 
Wong, S. W. L., Bishop, D. V. M., \& Ho, C. S.-H. (2009, May). A twin study of speech perception and production in L1 and L2 among Chinese children learning English as a second language. Paper presented at the 157th meeting of the Acoustical Society of America, Portland, OR.

Wong, S. W. L., Chow, B. W.-Y., Ho, C. S.-H., Waye, M. M. Y., \& Bishop, D. V. M. (2014). Genetic and environmental overlap between Chinese and english reading-related skills in Chinese children. Developmental Psychology, 50, 25392548.

Wong, S. W. L., Chow, B. W.-Y., Ho, C. S.-H., Waye, M. M.-Y., \& Bishop, D. V. M. (2013, July). The interplay among speech, phonology and word recognition in Chinese children learning
English as a second language. Paper presented at the 20th meeting of the Society for the Scientific Study of Reading Conference, Hong Kong.

Wong, S. W. L., Ho, C. S.-H., Chow, B. W.-Y., Waye, M., \& Bishop, D. V. M. (2010, July). Models of speech perception and production, meta-linguistics skills and reading development in Chinese children learning to read English as a second language. Paper presented at the 17th meeting of the Society for the Scientific Study of Reading Conference, Berlin, Germany.

Zheng, Y., Ding, X., Chen, Y., \& He, M. (2012). The Guangzhou twin project: An update. Twin Research and Human Genetics, 16, 73-78. 